\title{
The formation age and evolution of Kumtagh Desert
}

\author{
JinNian TANG ${ }^{1,2}$, ZhiZhu SU ${ }^{3}$, Feng DING ${ }^{1,2}$, ShuJuan ZHU ${ }^{1,2^{*}}$, YouHao E ${ }^{1,2}$, XinWei ZHAl ${ }^{4}, Z_{\text {ZhiYu Yl }}^{4}$, \\ HuJun LIU ${ }^{1,2}$, JinChun ZHANG ${ }^{1,2}$, FaMing $\mathrm{LI}^{1,2}$ \\ ${ }^{1}$ Minqin National Studies Station for Desert Steppe Ecosystem, Minqin 733300, China; \\ ${ }^{2}$ State key Laboratory Breeding Base of Desertification and Aeolian Sand Disaster Combating, Gansu Desert Control Research \\ Institute, Lanzhou 730070, China; \\ ${ }^{3}$ School of History and Culture, Shanxi University, Taiyuan 030006, China; \\ ${ }^{4}$ Lanzhou University, Lanzhou 730000 , China
}

\begin{abstract}
The ancient aeolian sand has been regarded as an indicator for the formation and evolution of a desert in the past. Kumtagh Desert is located at the northern fringe of Qinghai-Tibet Plateau. The first integrated scientific investigation to the desert was carried out during the period of 2004-2006. Kumtagh Desert is an ideal natural model for studying the formation and evolution of the desert because the Quaternary strata containing ancient aeolian sands are widely distributed. The integrated field investigation and studies on sedimentary, chronology and palynology of typical profiles named Suosuo gully, Xiaoquan gully and gravel body with ancient aeolian sand layers showed that Kumtagh Desert was probably formed as early as $2,097.7 \pm 314.7 \mathrm{ka}$ BP. During the period of $386.9 \pm 58.0 \mathrm{ka} \mathrm{BP}$ to $285.9 \pm 42.9 \mathrm{ka} \mathrm{BP}$, the desert largely expanded and formed its modern distribution pattern. The desert was originally developed in the southwest, subsequently, expanded to the north and northeast. The sedimentary facies of Suosuo gully profile revealed that the desert experienced at least 19 cycles of advance and inverse processes of desertification with an average period of $110 \mathrm{ka}$ in the Quaternary. The neotectonic movements played an important role in the formation, development and geomorphology of the desert. On one hand, the movements caused the formation of intermontane fault basin, which was further developed towards the closed drought basin, and caused the formation of natural environment. On the other hand, under the control of surrounding faults, the unique broom-shaped desert landscape was formed, and the gullies and sand ridges in this region experienced an abrupt directional change from north by west to north by east at the location of $39^{\circ} 45^{\prime}-39^{\circ} 55^{\prime} \mathrm{N}$. The unique landscape of gravel body that occurred widely in the northern desert was formed after $285.9 \pm 42.9 \mathrm{ka}$ BP. The results in this paper provide the scientific basis for studying the formation age and evolutionary process under the dry climate and environment in the northwestern China, and the uplifting of Qinghai-Tibet Plateau as well as its responses to the global climate changes.
\end{abstract}

Keywords: Kumtagh Desert; formation age; evolution; ancient aeolian sand

\section{Introduction}

The west, the east, the north and the south of Kumtagh Desert respectively borders Lop Nur region of Tarim Basin in Xinjiang, Dunhuang City of Gansu, the eastern Tianshan Mountains (Beishan Mountain), and Altun Mountains (Fig. 1). Kumtagh Desert $\left(90^{\circ} 00^{\prime}-94^{\circ}\right.$ $20^{\prime} \mathrm{E}, 39^{\circ} 00^{\prime}-40^{\circ} 50^{\prime} \mathrm{N}$ ) has a length of $280 \mathrm{~km}$ from east to west, and a width of $120 \mathrm{~km}$ from north to south. The desert, with an area of $2.29 \times 10^{4} \mathrm{~km}^{2}$, is the sixth largest desert in China (Ding et al., 2006), and is located in the inland area of Northwest China, where the rainfall is less than $10 \mathrm{~mm}$, and sandstorms occur frequently. Due to the harsh natural conditions and inaccessibility of vehicles, a few scientific researches were carried out in Kumtagh Desert until the end of the $20^{\text {th }}$ century (Wang, 2003). Sven (1997) once went to the northern fringe of Kumtagh Desert when he explored Lop Nur, and described the aeolian landforms and geographical features there. Since 1987 some researchers have made the studies in the northern fringe of the desert (Xia, 1987; Qu et al., 2003, 2004, 2005; Tang, 2008; Liu, 2009). They studied the basic

Received 2010-08-16, accepted 2010-12-22

doi: 10.3724/SP.J.1227.2011.00114

* Corresponding author: ShuJuan ZHU (E-mail: zhshj1999@163.com) 


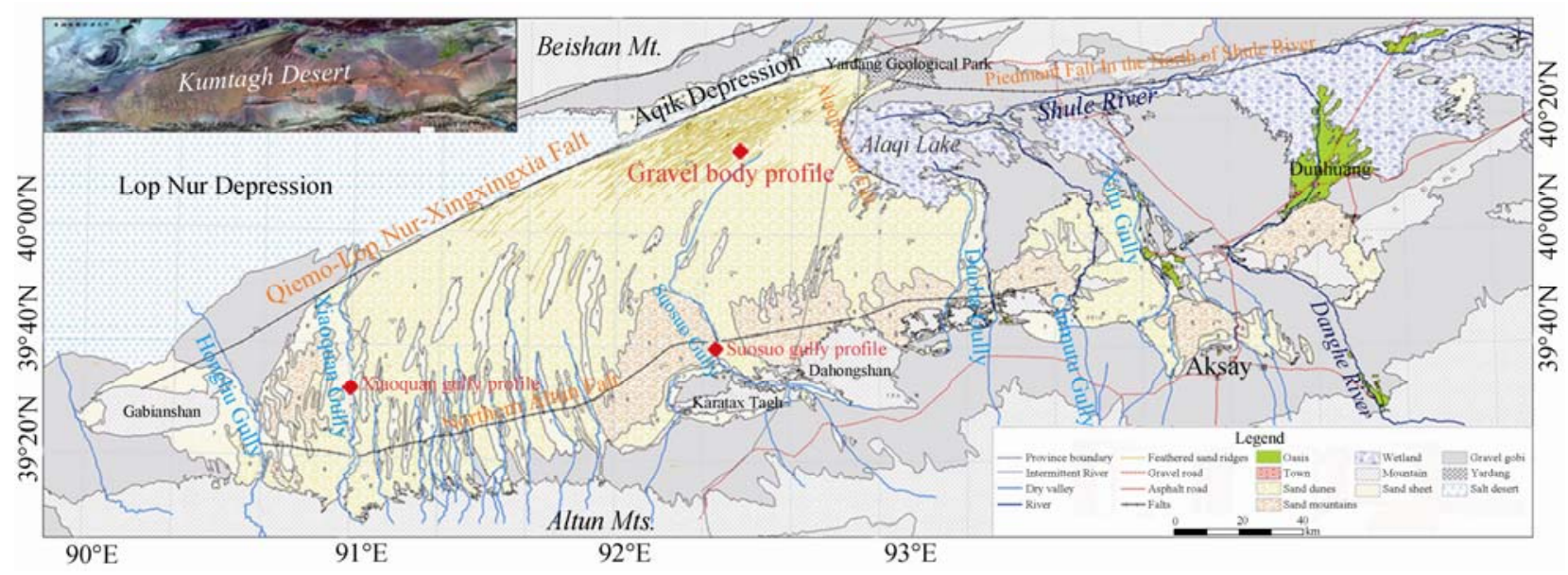

Fig. 1 Geology and geomorphology of Kumtagh Desert

characteristics, sand sources, the formation and evolution of the desert and feathered dunes in Kumtagh Desert by applying aerial and satellite images. However, the available researches were concentrated on some qualitative descriptions and indirect deductions by applying the geological data in the surrounding areas, and there is little information concerning the underlying strata of ancient aeolian sands that are the evidence of the source for the formation and evolution of the desert. The research on the underlying strata of ancient aeolian sands, by applying geological methods, is the main way for studying the origin, formation and evolution of sandy deserts (Edwin, 1993; Dong, 2002).

Gansu Desert Control Research Institute conducted the first integrated scientific expedition to Kumtagh Desert during the period of 2004 to 2006, and then valuable information was obtained, which provided a scientific basis for the later studies (E et al., 2006). The study revealed that Kumtagh Desert is a typical mobile desert. Although the area is not the largest one, the aeolian landforms are diverse and complex, with various dune types. Dune types of most deserts in the world can be found here, such as barchan dunes and dune chains, the complex longitudinal sand ridges, linear dunes, sand hills, checkerboard dunes, star-shaped dunes, pyramid dunes, reverse dunes and climbing dunes. Especially, the feathered dunes, the unique one in the world, are developed here. Therefore, Kumtagh Desert is not only an ideal natural laboratory for studying the aeolian landform and sand movement, but also an ideal site for studying the formation and evolution of sandy deserts. From the hinterland to the fringe of the desert, the underlying stratigraphic section where ancient aeolian sand exists, is exposed widely. Flood alluvial, lacustrine and aeolian facies consist of the strata. The desert is overlaid on the tilted alluvial flood plain in front of Altun Mountains. The terrain is high in south and low in north, with the elevation from $2,000 \mathrm{~m}$ to $800 \mathrm{~m}$. It is cut by south to north gullies originated from the northern foot of Altun Mountains. The maximum depth of the gullies is $120 \mathrm{~m}$.

Along the banks of the gullies, the stratum profiles consisting of alluvial facies or the mixture of alluvial and aeolian facies are exposed on the surface. In the north of the desert, the remains of changed water courses of ancient rivers can be found, e. g., a dry lake basin and gravel body (including gravel beams, cones, beaches and other forms) cut by ancient river bed. The strata of the sediments of lacustrine and aeolian facies, consisting of gray-green and red-brown mudstone, red clay and yellowish-gray or brown-yellow aeolian sand, are exposed on the surface. In Aqike Depression to Ghost City (Yardang Geological Park) in the north fringe of the desert, the strata of lacustrine facies consisting of fine sand, clay sand and clay are exposed. Some aeolian sand layers have high cementation, and where the calcified plant root tubes are densely distributed.

\section{Method}

During the exploration, the authors investigated the geological features of Kumtagh Desert and the profiles underlying natural outcrops in the hinterland. The typical profiles as Suosuo gully, Xiaoquan gully and the gravel body were selected, detailed description and 
measurement as well as systematic sampling were done. Suosuo gully and Xiaoquan gully profiles with the interbedded deposition of aeolian sands and alluvial-pluvial sediments are located at the left bank of mid-upstream of gully in the southern desert, the gravel body profile with the depositional configuration of aeolian sand and lacustrine sediment is located in the northern desert (Figs. 1 and 3). Eight aeolian sand samples for ESR dating were taken with steel-tube from freshly dug of Suosuo gully and gravel body profiles, and were analyzed at the laboratory of the Qingdao Institute of Marine Geology. Eleven alluvial sediment samples for pollen analysis were taken from Suosuo gully profile (see Fig. 3 for location) and were analyzed at the laboratory of Nanjing Institute of Geology and Palaeontology, Chinese Academy of Sciences. This article, based on the exploration and analysis, as well as the available data concerning regional geological features, studied the formation age and evolutionary process of Kumtagh Desert.

\section{Results and discussion}

\subsection{Ancient geographical environment and formation of the desert}

In terms of tectonics, the basement of the eastern region of Lop Nur depression where Kumtagh Desert is located is the eastward extension of the Tarim platform. It is between the tectonic belt of Beishan Mountain (eastward extension of Tianshan Mountains) and the North Altun tectonic uplift, and at the narrowest part of the folding system between Tianshan Mts. and Kunlun Mts., and at the joint point between Qilian Mts. tectonic and Sino-Korean sub-platform. Therefore, there are strong tectonic activities here. Field investigations and geological literatures showed that Kumtagh Desert is surrounded by the fractures (Fig. 1), with Altun fault in the south and Jinyan Mountain in the west. It is extended towards Akesai, passing Lapei spring to Annan dam, with the direction of NE70 . Its southwest edge is dominated by the Qiemo-Lop Nur-Xingxingxia fault zone, with the direction of $\mathrm{NE} 65^{\circ}$, thus a $100 \mathrm{~km}$ long NE cliff was formed, with a height difference of 30-50 m. Its northern part is the piedmont fault, extending from east to west, and it is the western extension of Yumen Pass-Anxi-Qiaowan buried fault, which is the northern fault-fold belt of Yumen Pass in Beishan Mountain structural belt; its eastern edge is Alaqihuwan buried fault, thus the desert edge became a concave here. As surrounded by the faults, the desert is broom-shaped and the barrier platform was twisted. In geomorphology the gullies originating from Altun Mountains with running direction of south-north (such as Suosuo gully and Xiao

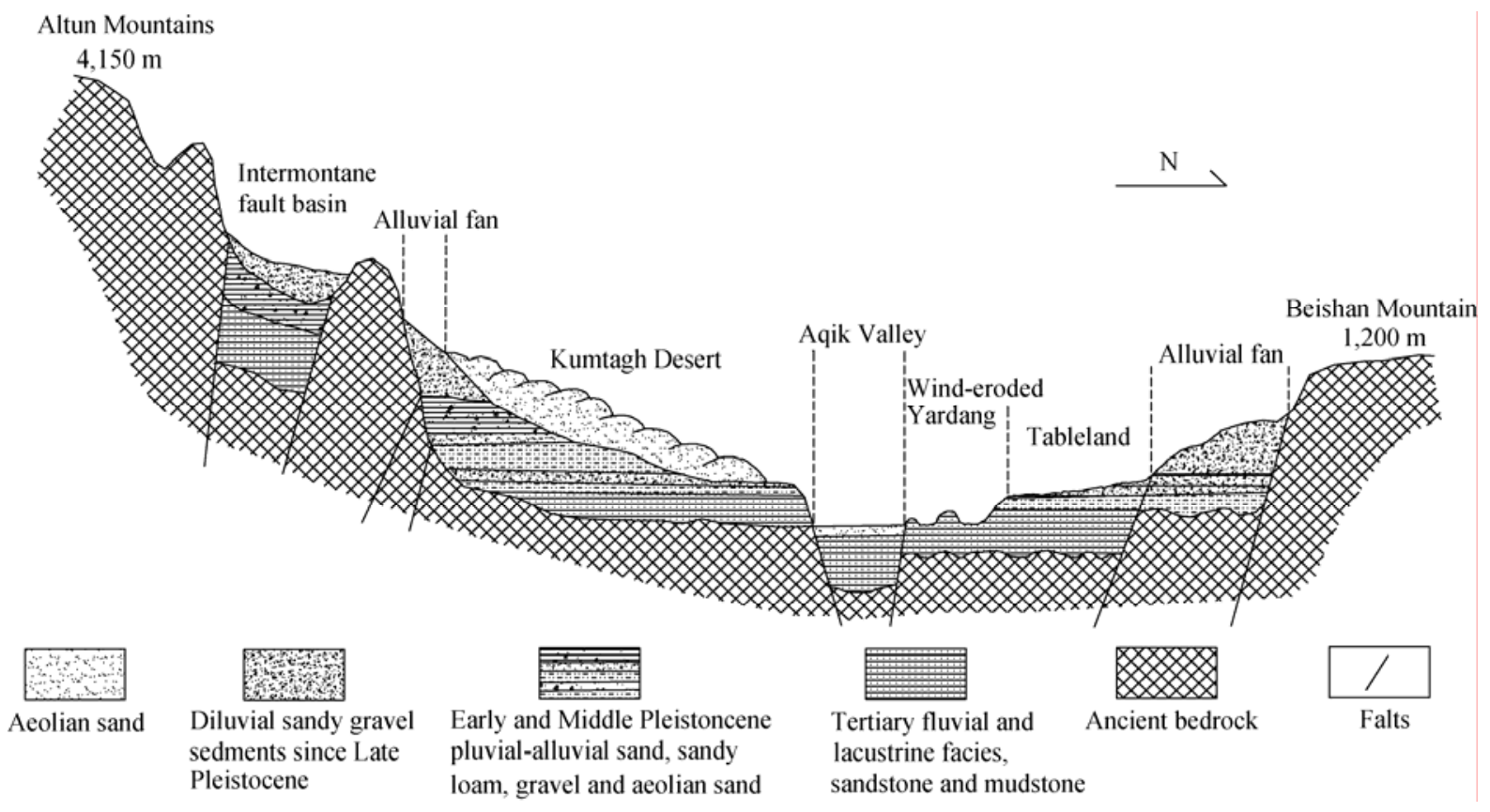

Fig. 2 Sketch map of geologic profile of Kumtagh Desert and its adjacent area 
quan gully) were formed and there is a sudden bend for sand ridges at the direction of $39^{\circ} 45^{\prime}-39^{\circ} 55^{\prime} \mathrm{N}$. As a result, its direction was changed from north by west to north by east (Fig. 1).

The formation and evolution of Kumtagh Desert is closely related to the ancient geological environment, and it is the result of neotectonic movement (Wang, 1987a; Jing et al., 1993; Qu et al., 2005; E et al., 2006). Since the late Miocene, there were more up-and-down movements, Tianshan, Kunlun and Altun mountains experienced dramatic uplift. The folds and faults were developed well in the piedmont zone. Due to the different uplift of tectonic movement and the regional difference of tectonic change in intensity, the folds and faults occurred in Tarim Basin and the east of Lop Nur region. Because of strong piedmont depression, a lot of ladder-typed horst block was formed, resulting in the tectonic differentiation (Wang, 1987b; Wang and Zhao, 2001). The secondary tectonic units, such as Lop Nur fault terrace, Hala Noor bend, Beishan block and Aqik Valley depression, were dismembered (State Seismological Bureau Studying Team of "the Altun Active Fault Zone", 1992). Kumtagh Desert is the development of the northern piedmont depression of great Altun Mountains. It, together with the uplift of the Beishan Mountain, formed the tectonic basin (Fig. 2), which laid a preferential foundation for the formation of the desert. Due to the structure differentiation and the blocking of alluvial fans, three centers of water catchments were formed, and they are located in Longcheng-Bailongdui in the north of Lop Nur, in the south of Bayi Spring in Aqik Depression, and in the north of Dunhuang City (Wang and Zhao, 2001). A thick sedimentary sandstone layer was formed due to accumulation of a large number of fragments, which offered plentiful sources for the formation of Kumtagh Desert.

The sedimentary assemblage and Quaternary biostratigraphy in the hinterland of Kumtagh Desert is shown in Fig. 3. In Quaternary, the landform of Kumtagh Desert has been the same as it is today. However, the geomorphologic feature, deposit type, climate and environment experienced new development at this time. The field surveys, image analyses (aerial photos and satellite images) and regional geological data indicated that the desert and the area near Lop Nur were overlaid by the various types of Quaternary sediments, including pluvial, alluvial, lacustrine and aeolian sediments in the late Tertiary. There are obvious differences in the spatial distribution of the composition of sedimentary facies. Total characteristics of the distribution pattern are: the pluvial deposit in the north and south of the desert, the combined facies of alluvial and aeolian deposits in the center and west of the desert, the combined facies of lacustrine and aeolian deposits in the north and east. In the north and south of the mountains, the ancient bedrock is exposed, and a few Tertiary red stratas are exposed, being scattered on the terrace in the front of the mountains.

\subsection{Characteristics of stratigraphic sediments and the desert age}

The formation age of the desert is mainly determined by the aeolian sand strata. Figure 3 shows three typical stratigraphic profiles exposed in different parts of the desert. Suosuo gully profile is on the left bank of the upstream of Suosuo gully in the southern desert. The thickness of the profile is $74.6 \mathrm{~m}$ with 251 layers. Among them, there are 18 layers of grayish yellow or brownish yellow aeolian sands, and one layer is gravel with foothill facies, and others are alluvial-pluvial layers with yellowish gray or cyan gray coarse sand, medium-sized sand, fine sand, silty sand, sandy silt and clay silt. Based on the dating results, the Quaternary strata of the profile were divided into the Lower Pleistocene $\mathrm{Q}_{1}$, Middle Pleistocene $\mathrm{Q}_{2}$, Upper Pleistocene $\mathrm{Q}_{3}$ and Holocene Series $\mathrm{Q}_{4}$ (Fig. 3). Aeolian sand can be seen in $\mathrm{Q}_{1}, \mathrm{Q}_{2}$ and $\mathrm{Q}_{3}$ with 5 layers, 11 layers and 2 layers, respectively. Holocene $\mathrm{Q}_{4}$ is dominated by aeolian facies, showing a variety of landform by wind sand accumulation. The lower part of the exposed section is a layer of dark gray, gray brown and gray mottled gravels, with a thickness of about $6 \mathrm{~m}$; the gravel composition is complicated, consisting mainly of quartz, feldspar granite, metamorphic and volcanic rocks. The gravels, with poor sorting, have various different sizes ranging from $0.2 \mathrm{~cm}$ to $14 \mathrm{~cm}$ and the gravels with the sizes of 2-3 $\mathrm{cm}$ are dominant. The gravels, with the morphology of semi-sphericity and sub-angular, are at a semi-cemented state. There are few broken gravels, and almost no ancient gobi surface and wind-blade stone. According to lithology andstratigraphic correlation, the gravel layer can be judged as the Lower Pleistocene's Western conglom 

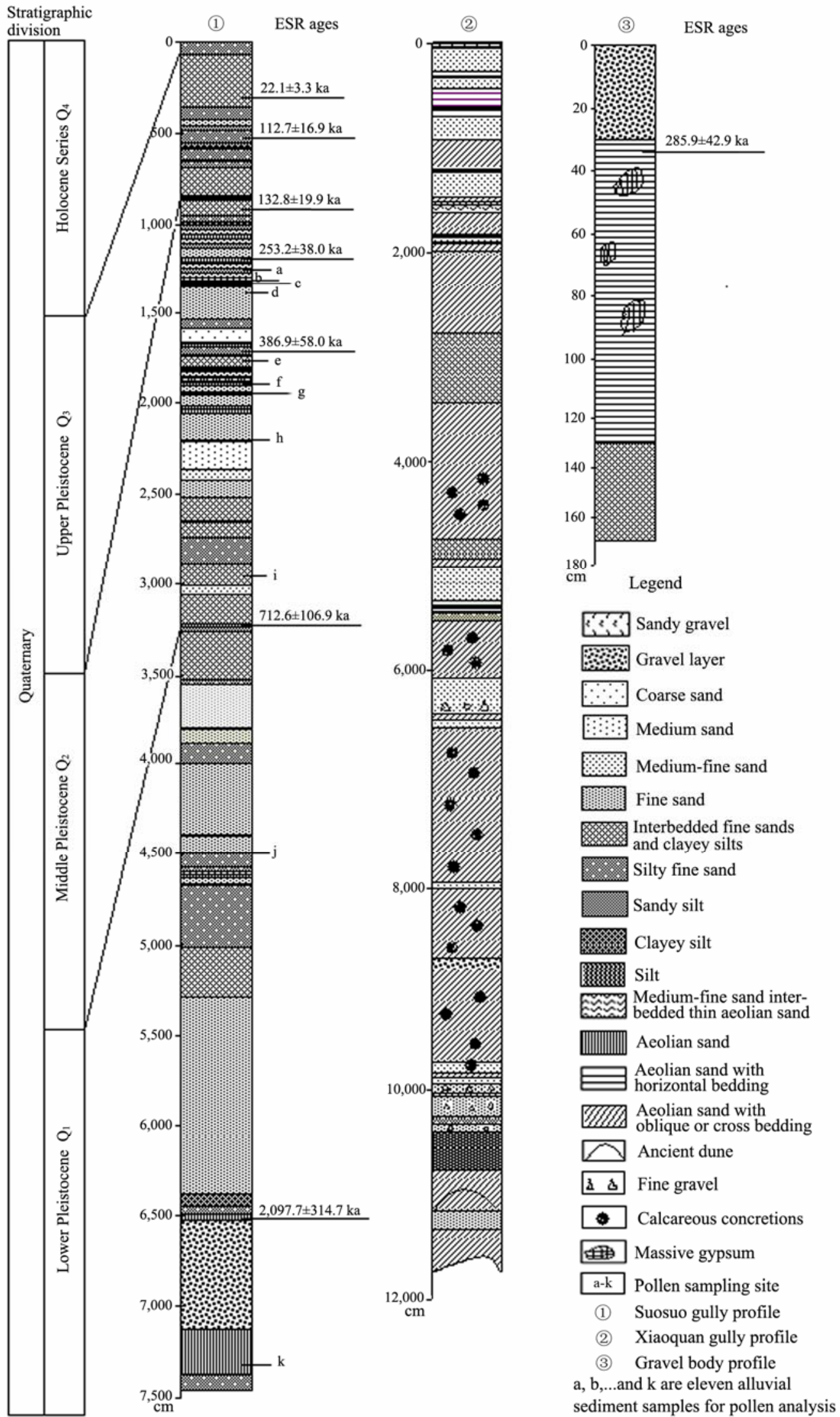

Fig. 3 The column profile of Quaternary strata in Kumtagh Desert 
erates or Yumen conglomerates, which is in accordance with the dating of overlying sand layer $(2,097.7$ \pm 314.7 ka BP) (Fig. 3). The regional stratigraphic data (Gansu Province Editorial Group of Stratigraphic Scale, 1980) indicated that there are the Lower Pleistocene's Yumen conglomerates in Hongliu gully, Duoba gully, Danghe reservoir and the Mogao Grotto, which are located in the mouths of the rivers and gullies in the northern foot of Altun Mountains. Yumen conglomerate can be regarded as the standard strata of the Lower Pleistocene in this area.

The profile of the middle reaches of Xiaoquan gully section is shown in Figs. 3 and 4. The thickness of the exposed section is $118.7 \mathrm{~m}$. According to the lithology and lithofacies characteristics, it can be classified into 58 stratigraphic units. The stratal configuration is dominated by the interbedded deposit of aeolian sands and alluvial-pluvial sediments. The aeolian sand layers are very thick. Among them, 28 layers consist of yellowish gray or brown-yellow fine sand, and 28 layers are flood alluvial-pluvial sediments with yellowish grey silty sand/clay. Except for the surface gravel layer, a thin layer of flood alluvial with gravel is interlining in the strata. There are 22 layers of aeolian sand above the gravel layer, and 6 layers below the gravel layer. Some ancient sand dunes in complete forms, with the heights of 1-4 $\mathrm{m}$, are exposed in a layer of aeolian sand (Fig. 5).

Gravel bodies, such as gravel cone, gravel beam and gravel beach are widely distributed in the north of Kumtagh Desert $\left(40^{\circ} 05^{\prime} \mathrm{N}\right)$. The maximum height of gravel cone/beam is $25 \mathrm{~m}$. Figures 3 and 6 show the profile of the gravel bodies. The upper part is 30 -cm-thick mottled gravel which is loose and angular, containing metamorphic rock, granite, volcanic rock, etc. The below part is the 1-m-thick aeolian sand layer that is developed horizontally, containing plenty of tabular or massive gypsum crystals. The underlying parts of aeolian sediments are the strata of fluvial and lacustrine facies dominated by the interbedded deposit of fine sand and clay sand. The characteristics of sedimentary structure manifest that gravel bodies are formed following the formation of the desert.

According to the ESR dating (Fig. 3), the formation age of the lower section of the aeolian-sand above the gravel layer in Suosuo gully is $2,097.7 \pm 314.7 \mathrm{ka} \mathrm{BP}$. Below the gravel layer, there is a 40 -cm-thick loose aeolian sand sediment, which is horizontally developed. This illustrates that aeolian activities existed in

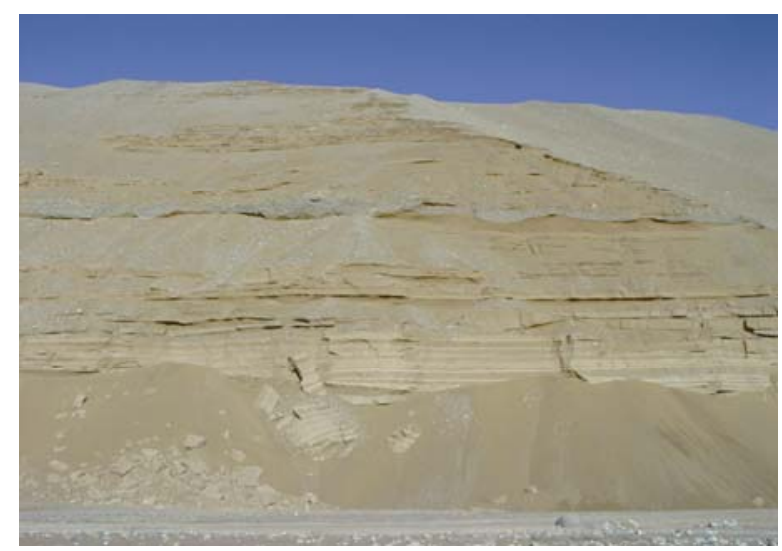

Fig. 4 Xiaoquan gully strata in western Kumtagh Desert

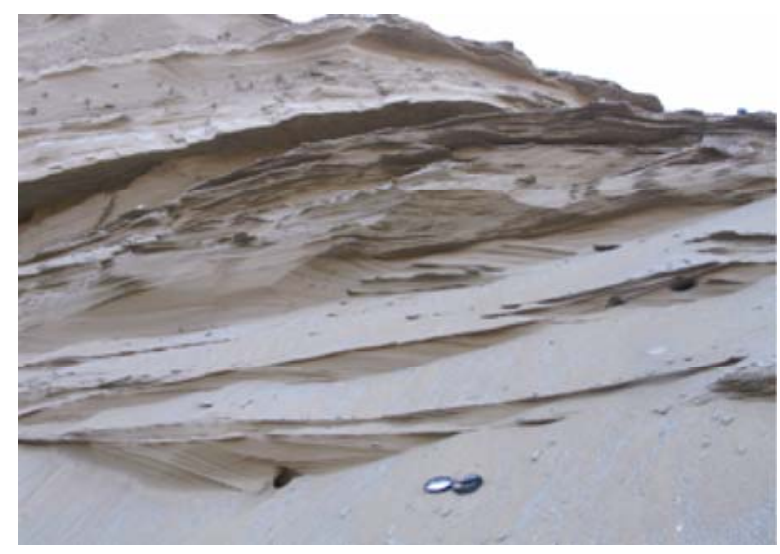

Fig. 5 Ancient sand dune contained in Xiaoquan gully strata

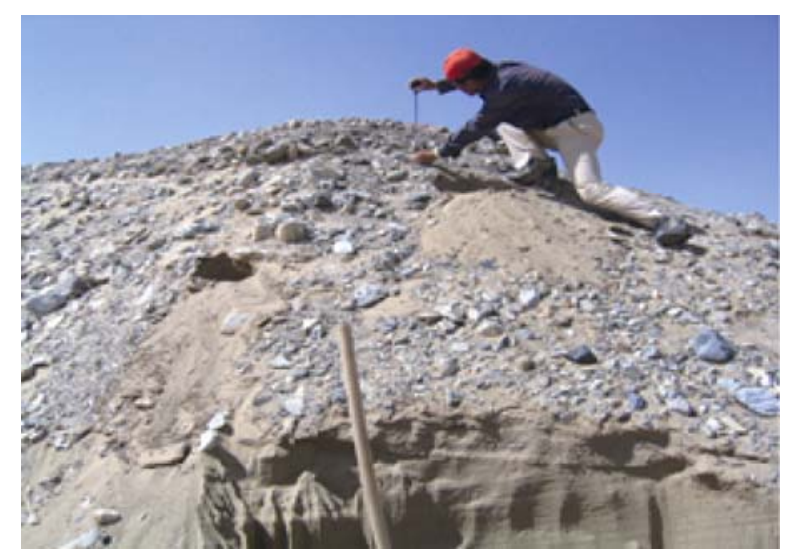

Fig. 6 Stratigraphic profile of gravel body

Kumtagh Desert from the Late Pliocene to Early Pleistocene when the desert started development. In Middle Pleistocene strata, the aeolian sand layers were increased significantly, totally 11 layers, mainly concentrating in the strata of middle and late periods (after $386.9 \pm 58.0 \mathrm{ka} \mathrm{BP})$. The depth of flood alluvial sediment in this period is obviously thinner than that in 
earlier years, which indicates that the aeolian activities in Kumtagh Desert were prevalent in the Middle and Late Pleistocene, and a large area of desert was formed. Wang (1986) and Xia (1987) investigated the Lop Nur and its neighboring areas and concluded the development of Kumtagh Desert started from the south, and then expanded northward. This conclusion is in accordance with our result. It can also be proved by the changes of aeolian sand thickness in the exposed parts of the gullies in the center and south of the desert. The aeolian sand layer became thinner from south to north. The aeolian sediment in Xiaoquan gully's stratigraphic section in the southwest of Kumtagh Desert has the most typical characteristics of sand deposits, a layer thickness with continuous distribution (the thickness can reach up to $14.9 \mathrm{~m}$ ), and is developed in the forms of bedding, such as plate bedding, gully-like bedding and cross bedding. The ancient sand dunes with complete form appeared in the lower strata, with the height of $4 \mathrm{~m}$ (Fig. 5). Accordingly, the formation of Kumtagh Desert started from southwest, and then extended northward and north-eastward. The gravel bodies were formed following the formation of the desert, and the age of the upper strata of the underlying gravel layer is $285.9 \pm 42.9$ ka BP. From the distribution of gravel cone, it can be concluded that Kumtagh Desert has formed at a large area in that time, then expanded to north in Late Pleistocene.

\subsection{The evolution of the desert}

The emergence of aeolian sand in strata is a sign of activation and expansion of a desert (Chen et al., 2001). The stratigraphic profile of Suosuo gully in Quaternary is dominated by the deposits of alluvial-pluvial sediments and aeolian sands, in which 19 layers consist of aeolian sand (including the modern desert). Kumtagh Desert experienced at least 19 cycles of advance and reverse processes of desertification, with an average cycle of about $110 \mathrm{ka}$. The aeolian sand accumulation on the surface of present Kumtagh Desert is the latest reflection to this circle. The specific processes of the Kumtagh Desert evolution are: in Early Pleistocene, with the significant uplift of the Qinghai-Tibet Plateau (in an uplift of over 1,000 m, the altitude of the plateau reached up to 2,500 m), Altun and Kitayama mountains also raised sharply, and then the regional climate changed from hot to cold and more precipitation (Wang, 1985; Wang, 1986). A large quantity of weathering products was transported to Kumtagh Desert and its nearby regions. The base was covered by strong conglomerate, shale and other materials, which provided abundant sand sources for the formation of Kumtagh Desert. The Lower Pleistocene strata $\mathrm{Q}_{1}$ appeared in the mouths of Hongliu, Xiaoquan, Suosuo and Duoba gullies as well as in Annanba region, which are located in the northern foot of Altun Mountains (Gansu Province Editorial Group of Stratigraphic Scale, 1980). The thickness of strata $\mathrm{Q}_{1}$ in Suosuo gully in the mid-south of the desert is $30 \mathrm{~m}$. The strata $\mathrm{Q}_{1}$ are dominated by the alluvial-pluvial facies, with a thin layer of aeolian sediment (Fig. 3). The pollen analysis showed that there was small amount of pollen in the $\mathrm{Q}_{1}$ alluvial-pluvial layer, in which xerophytes, such as Chenopodiaceae, Gramineae, Ephedra and Artemisia, etc. (Table 1) were dominant plants. The sediment in the strata $\mathrm{Q}_{1}$ and the assemblage characteristics of pollen showed that there were climate fluctuations between wet and dry, and generally the climate tended to be dry, and there were wind sand activities, which indicated the formation of Kumtagh Desert. In Middle Pleistocene, the piedmont fault terrace of Altun Mountains and Beishan Mountain experienced dramatic uplift. Aqike Depression had formed and experienced sedimentation (Wang, 1986; Wang, 1987a). Glaciers were well developed in the mountain lands around Tarim Basin, such as in Tianshan, Kunlun, Altun and Qilian mountains (Wang, 1985). The Ice Age was characterized by cold weather, rare precipitation and relatively stable deposit, and then the interglacial period was characterized by warm weather and melting snow.

The alluvial-pluvial, marine and lacustrine sediments are developed in the northern and southern piedmonts of Tarim Basin. Kumtagh Desert and Dunhuang have offered abundent sand sources for the formation of Kumtagh Desert. As the Altun Mountains' alluvial fan and Beishan Mountain terrace were covered by alluvial gravel, the pseudo-gobi was formed. In the region along Aqike Depression and Yumen Pass (to the east of Lop Nur) and in Longcheng-Bailongdui region (in the north of Lop Nur), thick lacustrine sediments are the Middle Pleistocene strata $\mathrm{Q}_{2}$, in which fine sand, clay powder and clay were deposited. The lacustrine strata were developed layer by layer with iron rust (Wang, 1986; Wang, 
Table 1 Characteristics of pollen assemblages in the stratigraphic profile of Suosuo gully

\begin{tabular}{|c|c|c|c|c|c|c|c|c|c|c|c|}
\hline \multirow{2}{*}{$\begin{array}{c}\text { Name of family } \\
\text { or genus }\end{array}$} & \multicolumn{11}{|c|}{ Sampling location } \\
\hline & a & $\mathrm{b}$ & $\mathrm{c}$ & d & $\mathrm{e}$ & $\mathrm{f}$ & g & $\mathrm{h}$ & $\mathrm{i}$ & $\mathrm{j}$ & $\mathrm{k}$ \\
\hline Pinus & 1 & 3 & 1 & 1 & & 2 & 1 & 1 & 4 & 2 & 1 \\
\hline Keteleeria & & & & & & & & 1 & & & \\
\hline Cupressaceae & & & & & & & & 1 & & & \\
\hline Ephedra & & 1 & & 2 & & 1 & 1 & & & & 4 \\
\hline Betula & & & & & & & 1 & & 1 & & \\
\hline Juglans & & & 2 & & 1 & 1 & 3 & & 1 & 2 & 4 \\
\hline Quercus & & 1 & & & & & & & 1 & & \\
\hline Ulmus & & & & & & & & & & & 1 \\
\hline Zygophyllum & & 1 & 1 & 1 & 2 & 11 & & 1 & & & \\
\hline Gramineae & & 1 & 1 & 1 & 3 & 5 & 4 & 3 & 2 & 4 & 3 \\
\hline Cyperaceae & & & & & & & 1 & & & & \\
\hline Chenopodiaceae & 6 & 4 & 2 & 1 & 3 & 16 & 8 & 5 & 3 & 2 & 6 \\
\hline Caryophyllaceae & & 1 & 1 & & & & 1 & & & & \\
\hline Leguminosae & & & & & & & 1 & & 1 & & \\
\hline Lespedeza & & & & & & & & & & 2 & \\
\hline Sprangum & & & & & 2 & 2 & & & & & \\
\hline Urtica & & & & 1 & 2 & & 1 & & 3 & 4 & 1 \\
\hline Artemisia & & & 1 & & 2 & 1 & & 1 & 1 & & 2 \\
\hline Cruciferae & & & 1 & & & & 1 & & & & \\
\hline Boraginaceae & & & & & & & & & & & 1 \\
\hline
\end{tabular}

Note: $\mathrm{a}, \mathrm{b}, \ldots$ and $\mathrm{k}$ are sampling locations in the ravine sections in Fig. 3

2001). Currently the strata are displayed as wind-eroded Yardang landform, which are scattered or concentrated here, with the heights of $10 \mathrm{~m}$ to $20 \mathrm{~m}$. In the Middle Pleistocene, the lacustrine and aeolian sand strata, consisting mainly of fine sand, silty sand, sandy silt and clay sand, were formed in the mid-south of the desert. The strata are loose and about $20 \mathrm{~m}$ in thickness (Fig. 3). The lithologic feature is consistent with that in the Lower Pleistocene. Exceptionally, the alluvial sediment layer gradually became thin, which indicates the climate was getting dry. Moreover, the aeolian sand layer significantly increased, from 5 layers to 11 layers, which indicated that more frequent wind sand activities occurred in Kumtagh Desert, and a vast area of the desert had been formed. The pollen content in the Middle Pleistocene is low in the desert, and the plant species of Chenopodiaceae, Gramineae, Zygophyllum, Artemisia, Ephedra (Table 1), were dominant. The significant increase of aeolian strata and the appearance of super-xerophytes' pollen illustrated that Kumtagh Desert and the desert climate had been basi- cally formed. In the middle and late period of Middle Pleistocene, the lacustrine sediment terrace uplifted in earlier age in the north of Lop Nur experienced dramatic wind erosion, and developed into Yardang landform (Wang, 2001).

When a great quantity of dust began to deposit in the gullies on the alluvial fans in the front of the northern piedmont of Altun Mountains, Kumtagh Desert began to expand at a large scale.

In Late Pleistocene $\left(\mathrm{Q}_{3}\right)$, Qinghai-Tibet Plateau and the mountains surrounding Tarim Basin experienced further uplift, which blocked southwest and northwest monsoon into its territory. The climate became drier, and aeolian activities occurred frequently. The $\mathrm{Q}_{3}$ sedimentary strata are characterized by the alluvial-pluvial sediments and aeolian sands which mainly consisted of fine sand, silty sand, sandy silt and clay sand (Fig. 3). In the region along Aqik Depression and Yumen Pass (to the east of Lop Nur) and in Longcheng-Bailongdui-Sanlongsha region (in the north of Lop Nur), the lacustrine strata that were formed early were eroded by strong wind, subsequently forming Yardang landform, which offered plenty of sand sources for the formation of Kumtagh Desert (Wang, 1986; Zheng, 2002). According to the records of aeolian sand deposits in the stratigraphic profile of Suosuo gully in Quaternary, the distribution characteristics of the stratigraphic profiles and the time sequence of sedimentation, the formation and development of Kumtagh Desert can be divided into three stages. The first stage is from the end of Pliocene to early Middle Pleistocene when obvious fluctuations between wet and dry climates occurred in the desert, but generally it tended to be dry with more aeolian activities, which indicated the desert began to be formed. The second stage is from mid Middle Pleistocene to the end of Late Pleistocene or the beginning of early Holocene, when the desert climate was formed. Aeolian activities were prevalent, and it is an important period for a large-scale expansion of the desert. The third stage started from Holocene when different aeolian landforms were well developed, and then the present desert landscape was formed.

In light of the differences in the formation reasons of Kumtagh Desert as well as the characteristics of the sediment structure, the evolution models of the desert can be summarized as follows: the southern foothills is characterized by aeolian sand overlapping on the alluvial-pluvial gravel or sandy alluvial gravel; and the 
north by the interbedded aeolian sand; the north by the mixture of aeolian sand, lacustrine sand and clay; the transitional zone in the middle part by the interbedded aeolian sand, alluvial sand and sandy clay.

\section{Conclusions}

(1) Kumtagh Desert is located at the belt where neotectonic movement was active. The neotectonic movement is vital to the formation and development of the desert. Under the actions of these movements, the inter-mountain basin was formed, and gradually evolved into closed arid basin, which created the natural environment for the formation and evolution of the desert. The role of the neotectonic movement can be seen in the present desert landscape. Under the control of the faults around the desert, the desert formed a unique broom-like shape, and the running direction of the gullies from Altun Mountains and sand ridges originated changed abruptly at the range of $39^{\circ} 45^{\prime}-39^{\circ} 55^{\prime} \mathrm{N}$, turning from the north by west to north by east.

(2) There were aeolian activities in Kumtagh Desert

\section{References}

Chen H Z, Jin J, Dong G R. 2001. Hodlocene evolution processes of Gurbantunggut Desert and climatic changes. Journal of Desert Research, 21(4): 333-339.

Ding F, Wang J H, Wei H D, et al. 2006. The scope and shape investigation of Kumtagh Desert. Scientific Research Monthly, (6): 66-68.

Dong G R. 2002. Research on Evolution and Formation of Desert and Desertification and Climatic Changes in China. Beijing: Ocean Press, 1-364.

E Y H, Su Z Z, Wang J H, et al. 2006. Outcome and scientific significance of integrated investigation in Kumtagh Desert. Journal of Desert Research, 26(5): 693-697.

E Y H, Wang J H, Yang P, et al. 2008. Evolution of palaeo-drainage system and its relationship with the formation of desert landform in the Kumtagh Desert. Acta Geographica Sinica, 63(7): 725-734.

Edwin D M (translated by Zhao X L). 1993. A Study on Global Sand Seas. Yinchuan: Ninxia Pepole's Press, 178-234.

Gansu Province Editorial Group of Stratigraphic Scale. 1980. Regional Stratigraphic Scale of Northwest China, Gansu Branch. Beijing: Geology Press, 51-67.

Jing C R, Wang S Y, Li J S. 1993. Introduction to Quaternary Geology. Beijing: Geology Press, 8-17.

Liu H J, Wang J H, Liao K T, et al. 2009. Type and distribution of geomoephology of aeolian sediment at region of Suosuo Vale of Kumtagh Desert. Arid Land Geography, 32(1): 87-94.

Qu J J, Zhen B X, Yu Q H, et al. 2003. The Yadan landform of Aqik valley in the east of Lop-Nur and its relationship with the evolution of the Kumtagh Desert. Journal of Desert Research, 23(3): 295-300. Qu J J. 2004. The Map of Kumtagh Desert. Beijing: Map Press of China.

Qu J J, Zuo G C, Zhang K C, et al. 2005. Relationship between the formation and evolution of the Kumtagh Desert and the regional neotectonic movement. Arid Land Geography, 28(4): 424-428. at the beginning of Early Pleistocene $(2,097.7 \pm 314.7$ ka BP) when the desert started development. Since Middle Pleistocene (386.9 $\pm 58.0 \mathrm{ka} \mathrm{BP})$, wind sand activities became prevalent, and the desert expanded at a large scale. In late Middle Pleistocene $(285.9 \pm 42.9$ ka BP), a vast area of the desert was formed. The desert was initially formed in southwest, and then expanded towards northeast.

(3) Kumtagh Desert had experienced 19 circles of advance and reverses processes since Early Pleistocene, with an average period of $110 \mathrm{ka}$. There is zonal difference in the evolution model at north-south direction.

(4) The gravel body, a unique landscape in Kumtagh Desert, was developed following the formation of the large-scale desert, and formed in the end of Late Pleistocene after $285.9 \pm 42.9 \mathrm{ka}$ BP.

\section{Acknowledgements}

This research was supported by Natural Science Foundation of Gansu Province (0803RJZH086) and National Natural Science Foundation of China (40961013).

State Seismological Bureau Studying Team of "the Altun Active Fault Zone". 1992. The Altun Active Fault Zone. Beijing: Earthquake Press, 1-194.

Sven A H (translated by Wan A H, Cui Y H). 1997. Expedition of Lop-Nur Region. Urumqi: Xinjiang People's Press, 1-32.

Tang J N, Wang J H, Su Z Z, et al. 2008. Grain size parameters and their distribution on feather-like dune of the Kumtagh Desert. Arid Land Geography, 31(6): 918-925.

Wang H Z. 1985. Palaeogeographic Atlas of China. Beijing: Cartographic Publishing House, 131-143.

Wang S J. 1987a. The cause of formation of Aqik valley. In: The Xinjiang Team of Chinese Academy of Science. Scientific Investigation and Study of Lop-Nur Region. Beijing: Science Press, 60-67.

Wang S J. 1987b. The preliminary study on neotectonic movement in the Lop-Nur Lake and its adjacent area. In: The Xinjiang Team of Chinese Academy of Science. Scientific Investigation and Study of Lop-Nur Region. Beijing: Science Press, 37-51.

Wang T. 2003. Desert and Desertification in China. Shijiazhuang: Hebei Science and Technology Press, 689-699.

Wang W X. 1986. A study on development history of the Quaternary deposits of the Lop-Nur Lake and its adjacent area. Quaternary Sciences, 7(2): 75-86.

Wang Y, Zhao Z H. 2001. Quaternary palaeogeography of Aqike depression, eastern Lop-Nur, Xingjiang. Journal of Palaeogegraphy, 3(2): 23-28.

Xia X C. 1987. The basic feature of Kumtagh Desert. In: The Xinjiang Team of Chinese Academy of Science. Scientific Investigation and Study of Lop-Nur Region. Beijing: Science Press, 78-94.

Zheng B X, Zhang L Y, Hu X H. 2002. Distribution and characteristics of landform and its formation period, west to Yumenguan, Gansu. Journal of Desert Research, 22(1): 40-46. 